\title{
Interfacial bond-slip relationship between Carbon Fiber Reinforced Polymer Plate and Concrete after High Temperature of Asphalt Paving Construction
}

\author{
Xin Yuan $^{a *}$ (1) Yuye Zhang ${ }^{b}$ (D) Chaoyu Zhua (i) Wei Zheng ${ }^{c}$ (i) Baijian Tang ${ }^{a}$ (i) \\ a School of Civil Engineering, Suzhou University of Science and Technology, Suzhou 215011, China. Email: yuanxin9988@163.com, \\ zhuchaoyu@126.com, tangbaijian@163.com \\ b Department of Civil Engineering, Nanjing University of Science and Technology, Nanjing 210094, China. Email: zyy@njust.edu.cn \\ c Suzhou Zhongcheng Access Bridge Co., Ltd. Suzhou, 215000, China. Email: robinwll@163.com \\ * Corresponding author
}

https://doi.org/10.1590/1679-78255782

\begin{abstract}
The bond-slip relationship of Carbon Fiber Reinforced Polymer (CFRP) plate-concrete after the influence of high temperature action of Stone Mastic Asphalt (SMA) paving was investigated in this article. Two groups of double shear specimens with different bonding length were designed and tested. Based on the test results, the failure modes of specimens, the strain distribution and the shear stress of CFRP-concrete interface were analyzed. Considering the influence of high temperature, the interfacial bond-slip constitutive model of CFRP plate and concrete after high temperature action of SMA paving construction was proposed. The proposed model can reflect the nonlinearity and interface softening behaviour of the CFRP plate-concrete interface constitutive relationship under special environment. Through the comparative study of exixting constitutive models, the interface bond-slip constitutive model proposed in this paper considers the effect of high temperature and has good agreement with the test results.
\end{abstract}

Keywords

Bond-slip constitutive model, Carbon Fiber Reinforced Polymer (CFRP)-concrete interface, double shear test, high temperature, aspahlat paving, debonding failure

\section{INTRODUCTION}

Due to the excellent material properties of Carbon Fiber Reinforced Polymer (CFRP), this material has been widely applied in the reinforcement of bridge structures (Siddika et al., 2019; Zhuang et al., 2018; Bocciarelli et al., 2018; Lepretre et al., 2018; Chataigner et al., 2018). Many scholars have carried out many investigations on the mechanical properties and failure mode of CFRP reinforced beams (Hawileh et al., 2014; Gallego et al., 2017; Chung et al., 2018). Studies have shown that the failure modes of CFRP-reinforced structures are often manifested as various types of debonding failure of CFRP-concrete interface (Zhang et al., 2017; Zeng et al., 2018; Rukavina et al., 2019). The ability to resist the deformation of FRP and concrete depends on the good bonding properties between CFRP and concrete 
(Yazdani et al., 2019; Wanga and Petrů, 2019; Shan et al., 2018; Li et al., 2018). Resaerch on the bond-slip relationship of CFRP-concrete interface is considered to be an in-depth study of CFRP strengthen methods applied to bridge (Yuan et al., 2019; Alhassan et al., 2019).

The interfacial bond-slip property between the CFRP plate and concrete has been widely investigated by researchers. Çelebi et al. (2016) conducted an experimental study on the interface of specimens with externally bonded CFRP plates. Based on the test results, a bond-slip model was proposed by considering the influence of anchorages. It is found that the interface bond stress can be improved by continuously introducing anchorages. Zhu et al. (2016) and Wang et al. (2018) investigated the bond behavior of CFRP-concrete beam with varying degrees of damage, and concluded that existing bond-slip model cannot accurately predict the interface characteristic of damaged CFRP-concrete structures. Rukavina et al. (2019) proposed a finite element model for simulating the bond-slip relationship of the fiber-reinforced concrete structure, and studied the failure mechanisms of reinforced concrete by considering different material characteristics. It is found that the proposed model can simplify the calculation process of non-linear behavior of fiber-reinforced concrete structure, and the bond-slip relationship can be better predicted as well. Yin and Fan (2018) and AI-Rousan and AL-Tahat (2019) systematically studied the influence of concrete surface on the bond-slip behavior of CFRP-concrete structures, a single shear test and a double shear test were respectively conducted by considering the roughness of the surface. Roughness parameter was introduced and proposed the optimum roughness for the best interface behavior. Haddad (2019) conducted an experimental study on the bonding behavior between CFRP and cracked concrete, 15 pull-off specimens were tested and its test results were analyzed. It indicated that the bonding behavior between CFRP and cracked concrete mainly affected by the concrete status, CFRP plate shape and anchorage measure.

In addition, several experts have conducted some research on the interface bond-slip performance under special circumstances. Firmo et al. (2015) and Dong and Hu (2016) studied the interfacial bond behavior of CFRP-concrete structures at elevated temperature ranging from $20^{\circ} \mathrm{C}$ to $120^{\circ} \mathrm{C}$, and found that elevated temperature has great effect on the strain distribution of bond interface. A simplified bond-slip model for CFRP-concrete interface at elevated temperature was proposed, and the nonlinear local bond-slip relationship can be better predicted. Pan et al. (2018) and Pan and Xian (2019) performed a single shear test on the bond behavior between CFRP and concrete under the influence of freeze-thaw cycles $\left(-20^{\circ} \mathrm{C}\right.$ and $30^{\circ} \mathrm{C}$ for 10 hours). A model for calculating the degradation of CFRPconcrete bond interface was proposed, and an environmental coefficient was introduced to predict the service life of CFRP-concrete structures. Liang et al. (2019) investigated the bond behavior of CFRP-concrete specimens under wetdry environment ( $5 \% \mathrm{NaCl}$ water for 0 to 360 days). It was found that the failure mode turns to the interface failure of adhesive and concrete as the wet-dry cycle increases. In addition, a prediction formula for calculating the fracture energy of interface was proposed, and its accuracy was verified by comparing with the test results.

The interface bond-slip performance was also investigated in bridge engineering. Rajai et al. (2016) evaluated the behavior of shear-keys of composite concrete bridges. It was found that the CFRP composites anchorage angle and length had a notable impact on corresponding slip and failure mode. An empirical model was proposed to predicte the shear-keys bond-slip behavior. Martin et al. (2017) applied a combination of a corrosion resistant carbon fiber reinforced polymer CFRP fabric and an efficient mortar to bridge deck slabs. It shows that the ultimate strength of bridge deck slabs can be increased significantly by CFRP based the investigation of the interface bond-slip performance of them. Yuan et al. (2019) researched the mechanical behavior of CFRP plate-reinforced bridge and the debonding failure mechanism of the test beams. It was shown that the average crack spacing was more effectively reduced by the additional anchoring measures. Mashrei et al. (2019) evaluated the bonding behavior of near surface mounted CFRPconcrete structure, several test beams were analyzed from their bearing capacity, deflection and failure mode. It was found that grooving technique have good improvement on the flexural capacity of CFRP reinforced beam.

Many experimental researches and analysis have been conducted on the bonding properties of CFRP and concrete under normal environment and special circumstance in recent years, but most of them do not consider the influence of special construction environment, such as asphalt paving process. Based on the reinforcement project of CFRP plate reinforced bridge roof with asphalt pavement (Figure 1), the interface behavior of CFRP-concrete after asphalt paving action is investigated. Since the $50 \mathrm{~mm}$ thick Stone Mastic Asphalt (SMA) layer needs to be laid on the roof of the 
bridge, the CFRP plate reinforced concrete structure will be affected by the high temperature in the asphalt paving process. The mechanical properties of the reinforced structure may be changed due to the high temperature (Firmo et al., 2015; Dong and Hu, 2016; Jeon et al. 2016). Therefore, it is necessary to study the mechanical properties of CFRP plate-concrete structure after the high temperature action.

In this paper, the interfacial bond-slip constitutive relation of CFRP plate-concrete after high temperature effect of asphalt paving construction is studied. Several double shear specimens with asphalt paving action are tested, and the mechanical properties of material under similar circumstance are tested as well. The experimental results are analyzed from the failure mode, strain distribution and interfacial shear stress, and the changes of bond-slip characteristics after high temperature action are studied in this article. The interfacial bond-slip constitutive model of CFRP plate-concrete after high temperature action was proposed by referring existing models. The accuracy of the proposed model is verified by fitting with the experimental data.

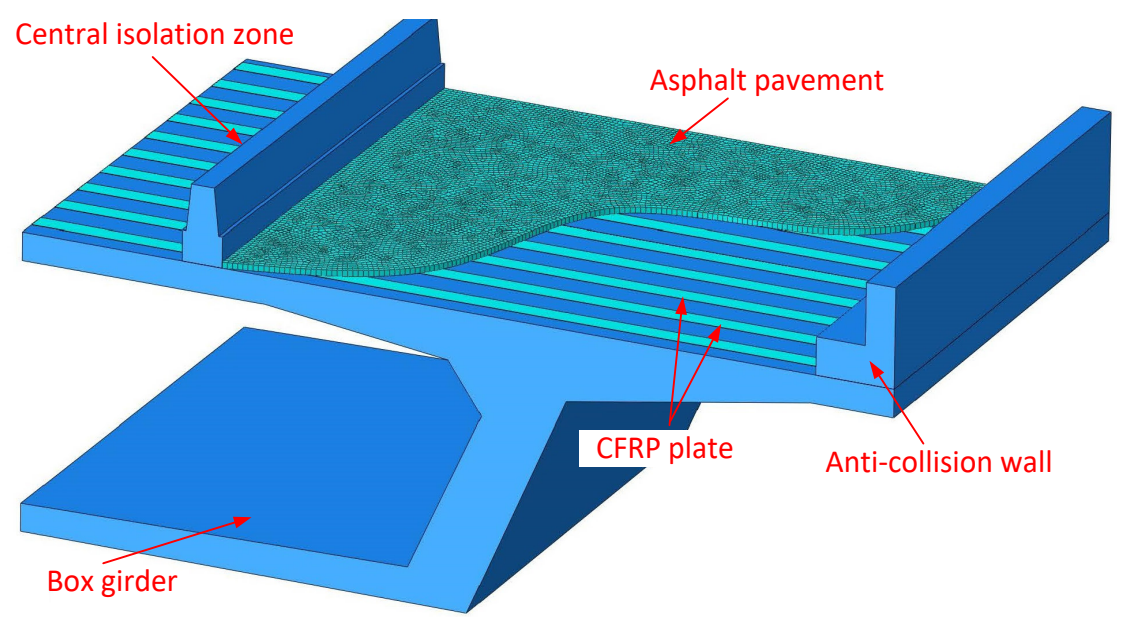

Figure 1 Reinforcement scheme of the bridge roof

\section{EXPERIMENTAL PROGRAMS}

\subsection{Specimen design}

To investigate the bond stress-slip relationship between CFRP plate and concrete after high temperature of asphalt paving construction, six double-shear test specimens with different bonding length were tested. Each specimen contains two concrete blocks and two pieces of CFRP plates. The size of each concrete block is $600 \mathrm{~mm} \times 150 \mathrm{~mm}$ $\times 150 \mathrm{~mm}$, and the size of the CFRP plate is $1630 \mathrm{~mm} \times 50 \mathrm{~mm} \times 1.4 \mathrm{~mm}$. The CFRP plates are pasted at the two sides of the concrete blocks. The detail of specimens is shown as Figure 2 .

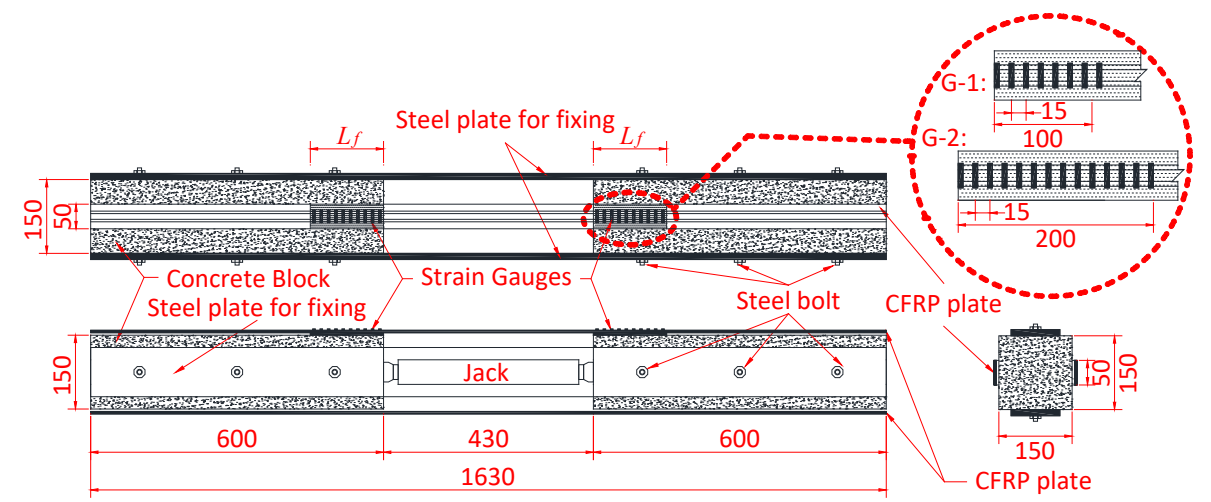

Figure 2 Detail of specimens (where $L_{f}$ is the bonding length of CFRP plate). 
The six specimens were divided into two groups G-1 and G-2. Each group contains three specimens, the CFRP bonding length of specimens in groups are $100 \mathrm{~mm}$ and $200 \mathrm{~mm}$, respectively. The specimen number of group G-1 are specimens DS-1 to DS-3, and the spcimens in the group G-2 are DS-4 to DS-6. To measure the strain distribution of the CFRP plate along the length, strain gauge was arranged along the centerline of the CFRP plate surface and the adjacent spacing of strain gauge is $15 \mathrm{~mm}$. Thus, the number of strain gauges on each specimens of the groups G-1 and G-1 are 8 and 14 , respectively.

\subsection{Experimental setup and temperature measurement}

To evaluate the high temperature effect of asphalt on the CFRP plates, the specimens was all buried at paving site in advance before the asphalt paving construction. The thickness of SMA (Stone Matric Asphalt) pavement layer is $5 \mathrm{~cm}$, the specimens were all buried by high temperature pavement layer in the paving process as shown in Figure 3 . The corresponding external environment conditions was as follows: the temperature is $26{ }^{\circ} \mathrm{C}$ and the humidity was $52 \%$. In the paving process, CFRP plates were directly affected by the high temperature asphalt paving action at the construction site.
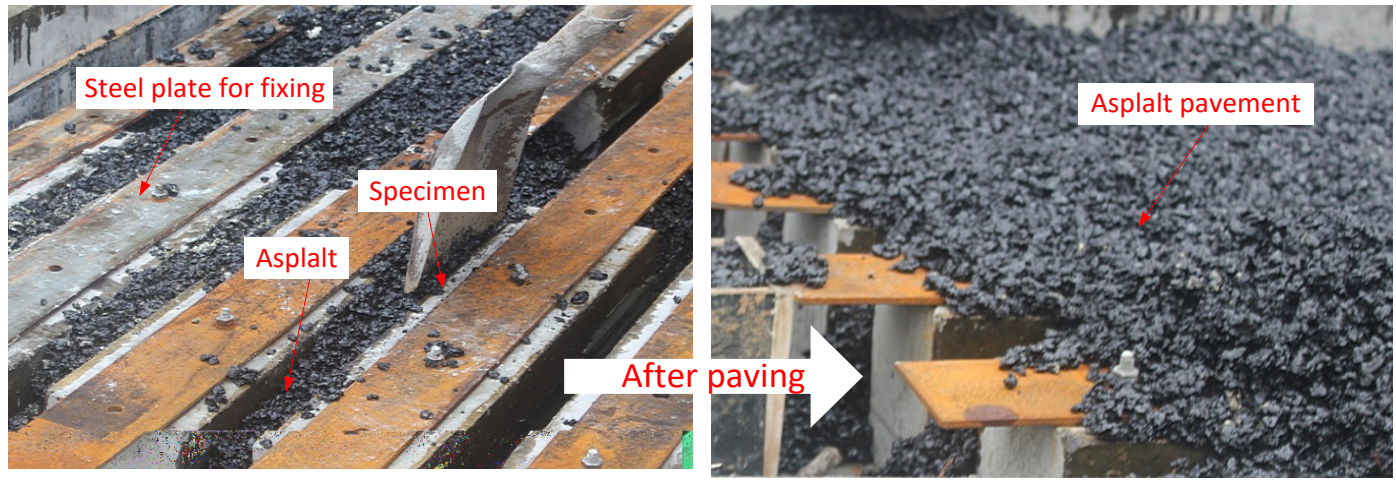

Figure 3 High temperature action of asphalt on the double shear specimen.

The epoxy mortar insulation layer as the original bridge deck paving scheme was applied on the surface of the CFRP plate of the specimens before asphalt paving construction, as shown in Figure 4. For testing the temperature of the asphalt pavement, the thermocouple probes were buried on different positions of the asphalt layer as shown in Figure 4. In addition, the temperature of the CFRP plate were also measured by arranging thermocouple probes on the upper and lower surface of the CFRP plates, as shown in Figure 4.

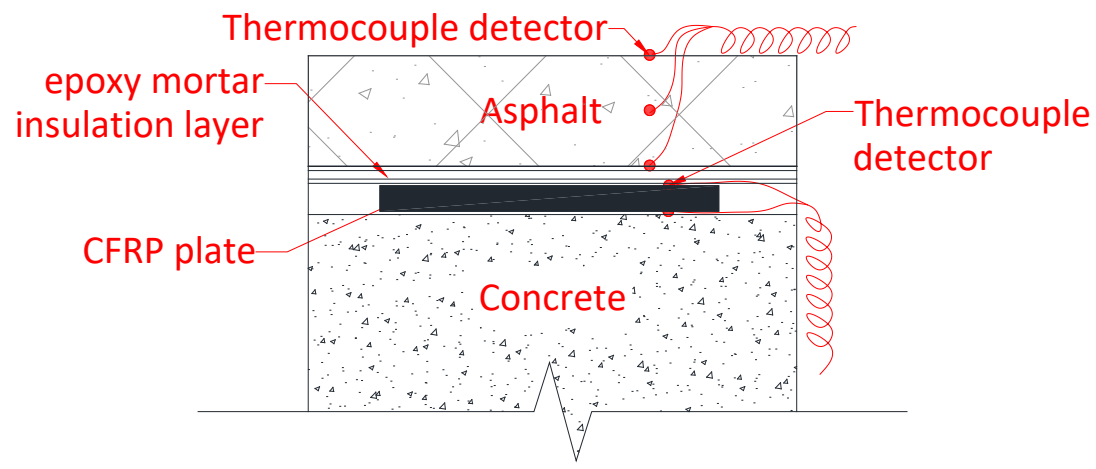

Figure 4 Pavement scheme and temperature test scheme.

The temperature changes of asphalt layer and CFRP plate during the high temperature action of asphalt paving process were measured. The temperature versus time curve of different positions of asphalt pavement and two sides of the CFRP plate are shown in Figure 5. 


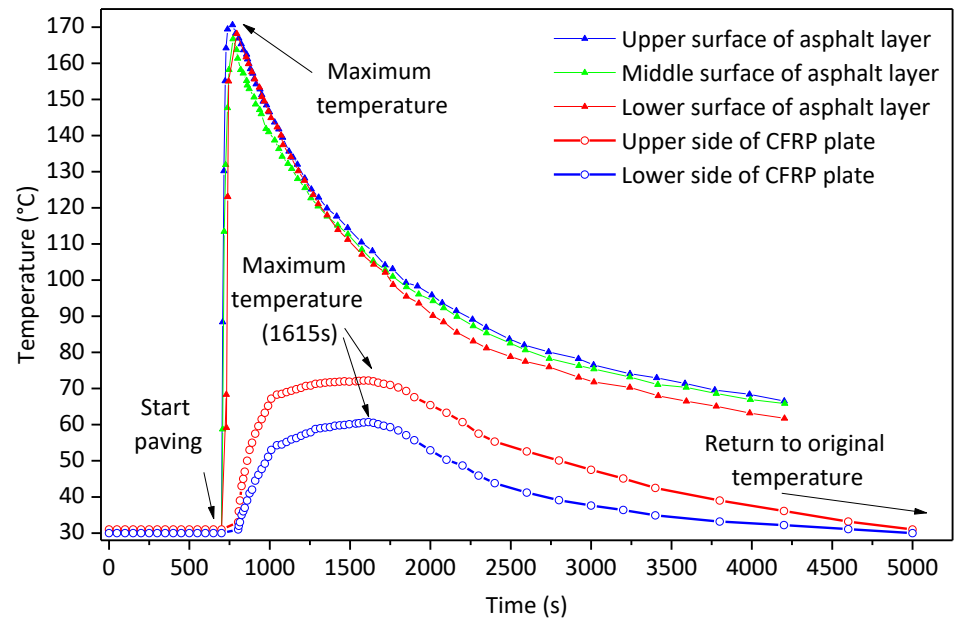

Figure 5 Temperature-time curves of asphalt layer and CFRP plate in the asphalt paving process.

The analysis of the asphalt temperature curve measured at different locations shows that the temperature of the asphalt layer rises rapidly after the paving starts, and the maximum temperature measured can reach up to $170{ }^{\circ} \mathrm{C}$. It can be seen from Figure 5 that the temperature of the upper surface of the CFRP plate rises within 815 seconds after the start of asphalt paving construction as well. The temperature reaches a maximum of $72.2{ }^{\circ} \mathrm{C}$ at 1615 seconds. During the period of 1615 seconds to 5000 seconds, the temperature gradually decreases and gradually reaches a steady state. The lower surface of the CFRP plate has a temperature change process similar to that of the upper surface, and its maximum temperature can reach $60.7^{\circ} \mathrm{C}$. For the temperature change curve of the upper and lower surfaces of the CFRP plate, both rising phases are steeper and the falling segments are relatively flat. By comparing with the temperature of the asphalt layer and the CFRP plate, it can be concluded that the CFRP plate and the interface of concrete -CFRP plate can be protected to a certain extent with the protection of epoxy mortar insulation layer.

After the high temperature effect of the asphalt paving construction on the double shear specimen was completed, the asphalt pavement and the epoxy mortar insulation layer were removed before the double shear test. A load test was applied to the double shear specimens, and the loading device is shown as Figure 6.

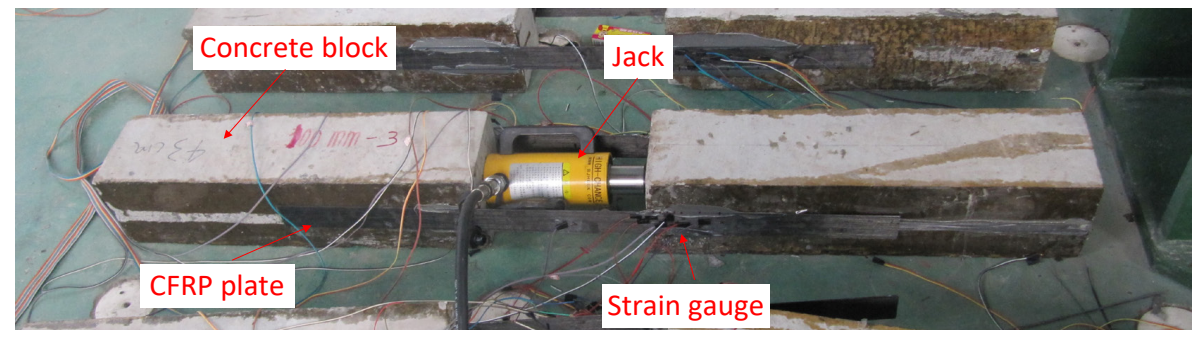

Figure 6 Double shear specimen and its loading device.

The load applied to the specimen for the first time was $1 \mathrm{kN}$ and gradually increased to the bearing capacity of the specimen until the specimen failed. The CFRP plate strain of the double shear specimen was measured by static strain gauges, and the data recording was performed for each stage of loading.

\subsection{Material properties test}

Considering the high temperature effect on material properties, a tensile test was conducted to test the tensile properties of CFRP plate at different temperatures. Ten pieces of CFRP plate specimens are prepared according to different temperature conditions. Five of them are normal temperature test specimens, and the other five are high temperature test specimens. The CFRP plate tensile specimens were prepared according to the requirement of the tensile test. Part of the specimens are shown as Figure 7(a), and the specimen on the test device after tensile test is shown as Figure $7(b)$. The CFRP plate specimens can be classified into two types with and without high temperature 
action $\left(80^{\circ} \mathrm{C}\right)$, and the tests were carried out under room temperature $\left(24^{\circ} \mathrm{C}\right)$. The high temperature was applied on the CFRP plates by directly embedding the CFRP plates into the asphalt layer. The results of CFRP plate tensile test are shown in Table 1.
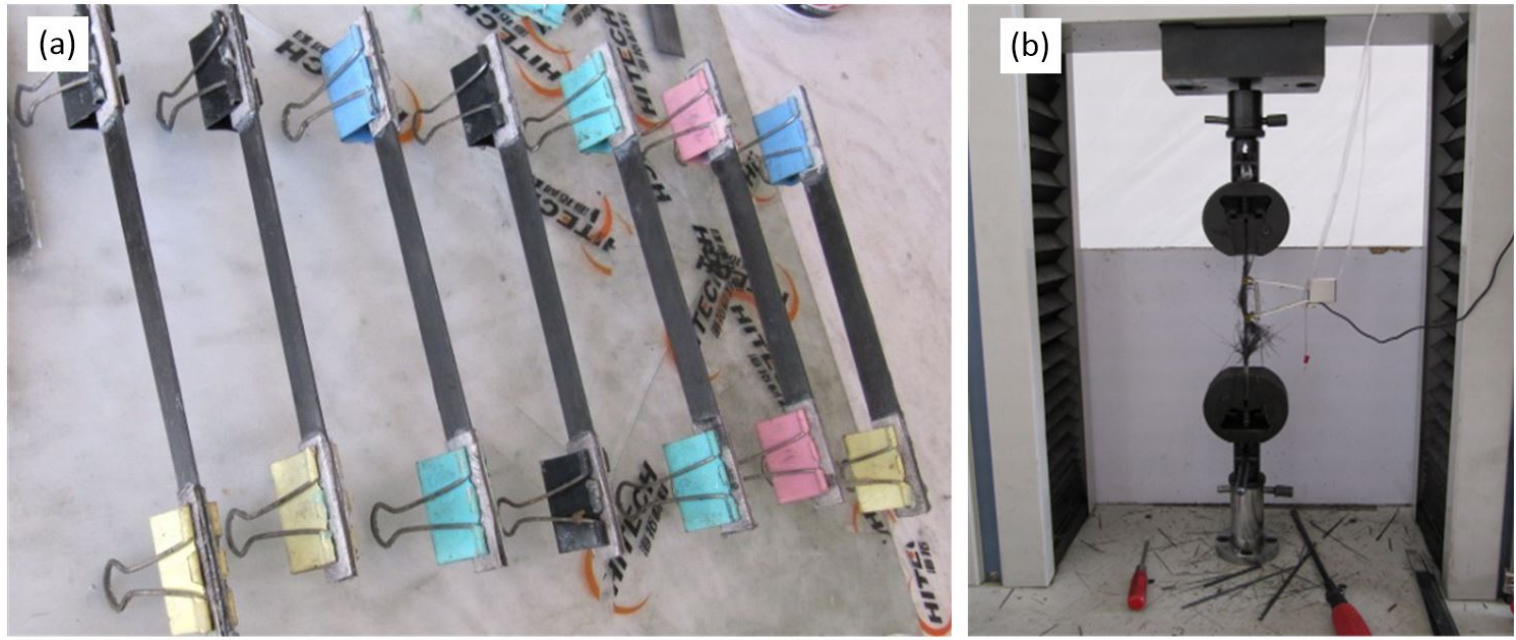

Figure 7 Tensile test for CFRP plate: (a) CFRP plate specimens; and (b) tensile test service.

Table 1 CFRP plate tensile test results at different temperature.

\begin{tabular}{|c|c|c|c|c|c|c|c|c|}
\hline Specimen number & Temperature action & $w / \mathrm{mm}$ & $t_{f} / \mathrm{mm}$ & $T_{m} / \mathrm{kN}$ & $\mathrm{f}_{\mathrm{tf}} / \mathrm{MPa}$ & $E_{f} / \mathrm{GPa}$ & $A_{f}(\%)$ & Failure mode \\
\hline $\mathrm{F}-1$ & \multirow{6}{*}{$\begin{array}{l}\text { Room temperature } \\
\left(24^{\circ} \mathrm{C}\right)\end{array}$} & 14.50 & 1.46 & 51.11 & 2414.41 & 157.12 & 1.45 & \multirow[t]{6}{*}{ Root fracture } \\
\hline $\mathrm{F}-2$ & & 15.39 & 1.45 & 49.95 & 2238.52 & 156.51 & 1.61 & \\
\hline $\mathrm{F}-3$ & & 14.31 & 1.48 & 54.67 & 2581.24 & 153.38 & 1.60 & \\
\hline $\mathrm{F}-4$ & & 14.80 & 1.45 & 51.18 & 2385.00 & 162.43 & 1.39 & \\
\hline $\mathrm{F}-5$ & & 14.88 & 1.44 & 49.96 & 2331.50 & 158.43 & 1.32 & \\
\hline Average value & & - & - & 51.37 & 2390.13 & 157.57 & 1.47 & \\
\hline $\mathrm{T}-1$ & \multirow{5}{*}{$\begin{array}{l}\text { High temperature } \\
\qquad\left(80^{\circ} \mathrm{C}\right)\end{array}$} & 15.49 & 1.44 & 42.38 & 1900.03 & 161.59 & 1.29 & \multirow[t]{6}{*}{ Root fracture } \\
\hline $\mathrm{T}-2$ & & 15.48 & 1.45 & 44.88 & 1999.55 & 141.09 & 1.60 & \\
\hline $\mathrm{T}-3$ & & 14.56 & 1.41 & 45.10 & 2196.90 & 146.96 & 1.80 & \\
\hline $\mathrm{T}-4$ & & 14.61 & 1.44 & 40.56 & 1928.09 & 152.21 & 1.18 & \\
\hline $\mathrm{T}-5$ & & 14.96 & 1.44 & 41.84 & 1942.30 & 149.02 & 1.49 & \\
\hline Average value & & - & - & 42.95 & 1993.37 & 150.18 & 1.47 & \\
\hline
\end{tabular}

Notes: $\mathrm{W}$ and $\mathrm{t}_{f}$ are the width and thickness of CFRP plate, $\mathrm{T}_{m}$ is the maximum tension stress, $\mathrm{f}_{t f}$ is the tension strength, $\mathrm{E}_{f}$ is the elastic modulus, and $\mathrm{A}_{f}$ is the elongation

It can be seen from the test results that the average tensile strength of CFRP plate under high temperature condition is $4.1 \%$ lower than that under room temperature. From the comparison of statistics, it can be learnt that the average tensile strength of interface between the concrete and CFRP plate can be reduced to some extent after the high temperature action of asphalt paving construction. The average elastic modulus at high temperature are $0.53 \%$ lower than that at room temperature. The average elongation of the CFRP plate at different temperatures are the same. In conclusion, the high temperature during the asphalt paving process will affect the interfacial property between the CFRP plate and concrete to some extents.

The multi-component acrylate low viscosity structural adhesive used in this study is K-801, and the CFRP plates are made of special resin and $12 \mathrm{~K} / 24 \mathrm{~K}$ high strength carbon fiber. Its tensile strength is generally more than $2300 \mathrm{MPa}$, the elastic modulus is more than $150 \mathrm{GPa}$, and the elongation is over $1.4 \%$. The properties of colloids were tested at different temperature as well. During the test, it can be observed that the colloid starts to soften at $90{ }^{\circ} \mathrm{C}$. As the temperature increases, it will become rubbery, and the surface of the colloid will slowly oxidize and turn yellow. When 
the temperature returns to normal temperature, the hardness gradually recovers. Table 2 presents the test results of colloid at different temperatures.

Table 2 Material properties of colloid at different temperatures (Unit: $M P a$ ).

\begin{tabular}{|c|c|c|c|c|c|}
\hline \multirow[t]{5}{*}{ Compressive strength } & Specimen number & $T=28^{\circ} \mathrm{C}$ & $T=150^{\circ} \mathrm{C}$ & $T=160^{\circ} \mathrm{C}$ & $T=170^{\circ} \mathrm{C}$ \\
\hline & $\mathrm{C} 1$ & 78.8 & 78.9 & 84.6 & 86.6 \\
\hline & $\mathrm{C} 2$ & 75.9 & 81.5 & 79.5 & 86.3 \\
\hline & C3 & 80.3 & 83.4 & 85.3 & 85.9 \\
\hline & Average value & 78.3 & 81.3 & 83.1 & 86.3 \\
\hline \multirow[t]{5}{*}{ Flexural strength } & Specimen number & $T=28^{\circ} \mathrm{C}$ & $T=150^{\circ} \mathrm{C}$ & $T=160^{\circ} \mathrm{C}$ & $T=170^{\circ} \mathrm{C}$ \\
\hline & B1 & 84.0 & 90.6 & 98.3 & 93.0 \\
\hline & B2 & 84.4 & 81.7 & 96.7 & 102.1 \\
\hline & B3 & 75.2 & 84.5 & 96.8 & 105.4 \\
\hline & Average value & 81.2 & 85.6 & 97.2 & 100.2 \\
\hline
\end{tabular}

It can be seen from the test results that the compressive strength and flexural strength of the colloid are increasing as the test temperature increases. The reason is that the intermolecular motion is hindered at normal temperature and the curing reaction between materials is incomplete. After the heating, the intermolecular activity is intensified, and the curing reaction continues, so the material properties are improved to some extent after the high temperature. It indicated that the performance of the colloid increases more obviously as the test temperature increases within the allowable temperature range. Therefore, proper heating is advantageous for the improving the property of colloid.

The concrete block is made of cement, sand and gravel, and the strength grade of the concrete block is C25, which compressive strength is $28 \mathrm{MPa}$ and the tensile strength is $1.8 \mathrm{Mpa}$. The elastic modulus of C25 concrete is $2.80 \times 10^{4}$ $\mathrm{MPa}$, and the Poisson's ratio is 0.2 . The standard value of concrete axial compressive strength and axial tensile strength are 16.7 MPa and 1.78 MPa, respectively. Hager (2013) studied the material performance of concrete at different temperatures. The study has shown that when the temperature is asphalt paving temperature, it has little effect on the concrete structure. Therefore, the influence of asphalt temperature on the concrete block is not considered in this paper.

\section{EXPERIMENTAL RESULTS AND DISCUSSION}

\subsection{Failure modes of specimen}

The failure modes of the double shear specimen can be divided into two types. The first type of failure mode appears in specimens DS-2 and DS-6, as shown in Figure 8(a). In this type of failure mode, the CFRP plate firstly debonded from the bonding end, and the damage position is away from the bonding interface. Therefore, the debonding damage at this time cannot be strictly regarded as failure. As the normal stress and shear stress increase, cracks will be generated. At this time, the debonding failure of specimen actually occurs, so the first type of failure mode is the split tensile failure of the protective layer. The second type of failure mode appears in specimens DS-1, DS3, DS-4 and DS-5, as shown in Figure 8(b). In this type of failure, the CFRP plate begins to debonding from the position near the loading end. A thin layer of concrete is adhered to the CFRP plate after debonding, and the debonding failure occurs at the bonding interface between the concrete layer and the adjacent concrete resin. The second type of debonding failure is the bond failure of the CFRP plate. 

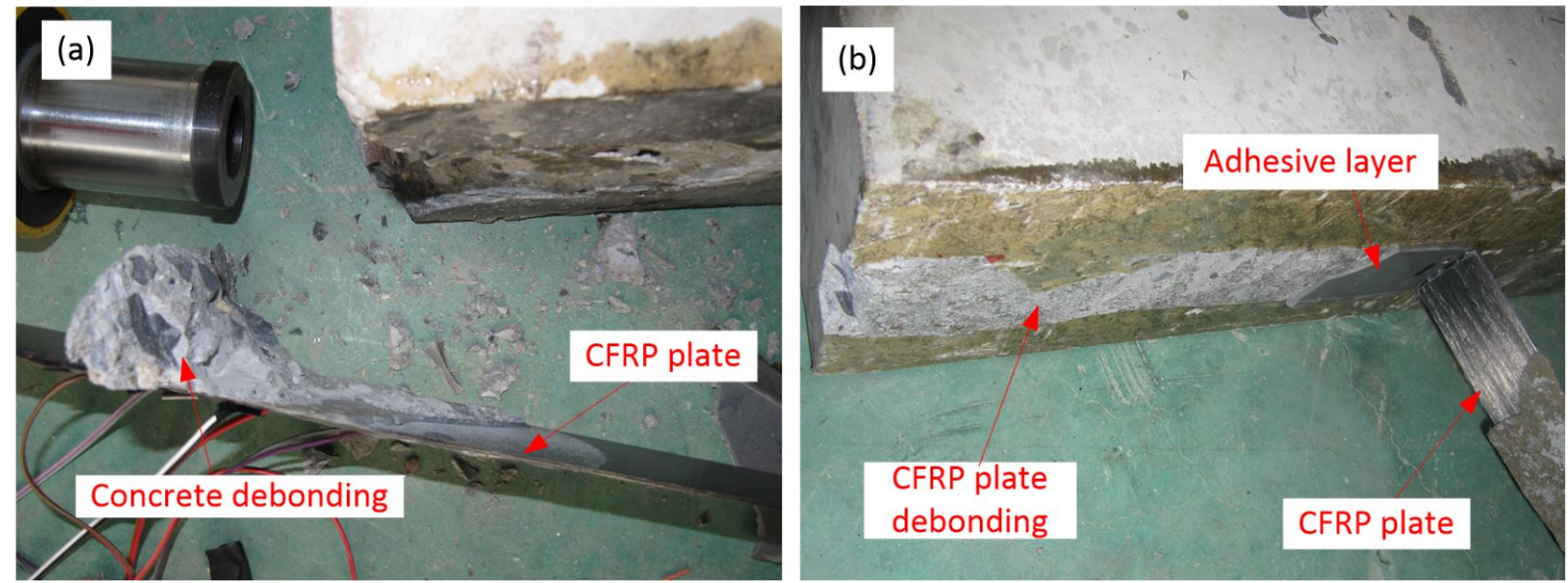

Figure 8 Failure modes of double shear specimen: (a) first type of failure mode: concrete debonding; and (b) second type of failure mode: CFRP plate debonding.

\subsection{Strain distribution of CFRP plate}

The strain at different positions of the CFRP plates under different load levels were measured by the static strain gauges, and the test results are shown in Figure 9. The horizontal axis represents the distance of the measuring point from the bonded end of the concrete, and the longitudinal coordinate is the strain of the CFRP plate.
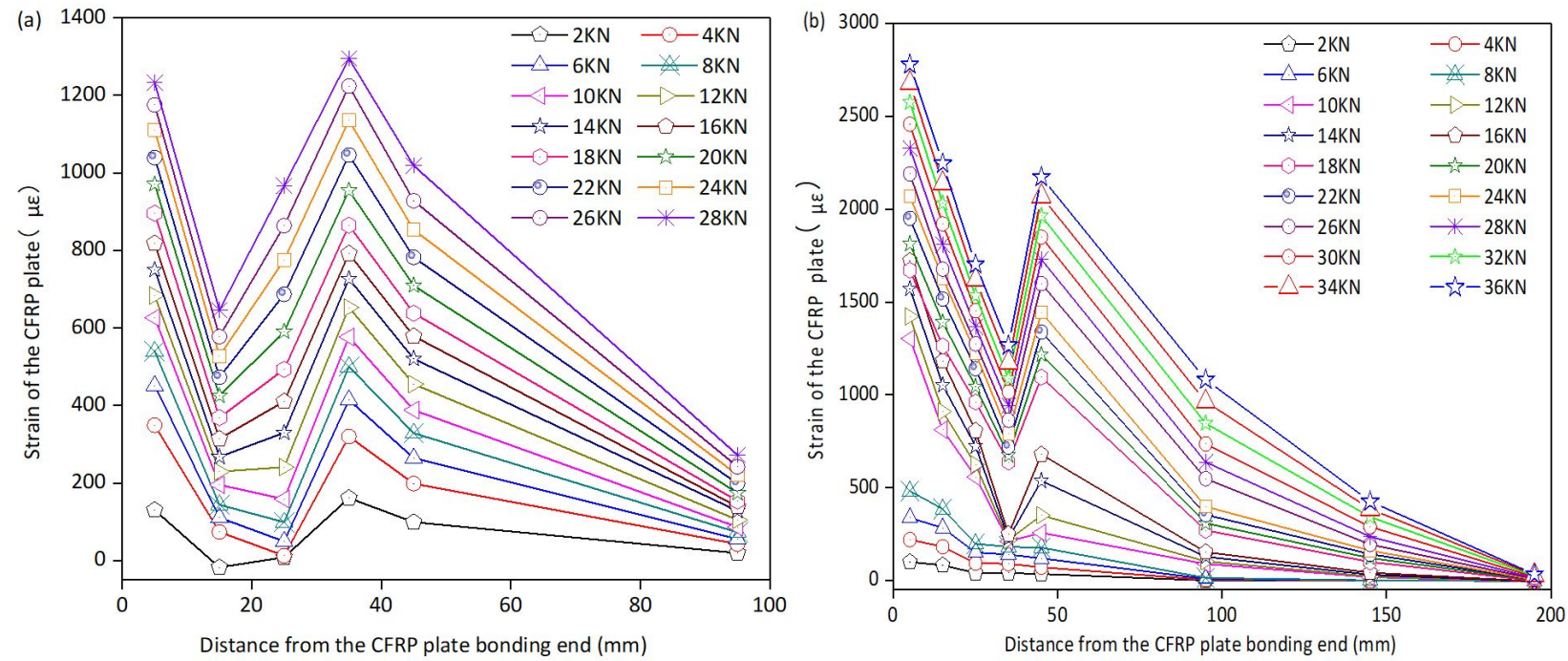

Figure 9 Strain distribution of CFRP plate under different loads: (a) specimens in G-1; and (b) specimens in G-2.

It can be seen from the figures that the strain change trends of the CFRP plates of the specimens in groups G-1 and $\mathrm{G}-2$ are basically similar. There is a turning point in the curve that represents the location where the damage stress is reduced. Stress redistribution occurs after the load continues to increase. When the load is small, the strain distribution near the loading end is linear. As the load increases, the length of the CFRP plate participating in the force increases, and the strain value of the CFRP plate near the loading end also increases. However, the strain at the effective debonding length position of the CFRP plate does not increase with the load value.

\subsection{Interface shear stress}

For the double shear specimens subjected to the high temperature action of asphalt paving construction, a large number of strain gauges were pasted along the length direction of the CFRP plate before the test. The strain values at various positions of the CFRP plate under different load levels can be measured during the test. The local bond shear stress $\tau$ of the CFRP plate can be obtained by calculation from the test values of adjacent strain gauges. It is considered 
that the strain measurement points cannot be infinitely tightly arranged. Moreover, the distribution of the cracks in the concrete near the interface corresponding to the measuring point have a great influence on the measured CFRP plate strain. If there is an interfacial debonding crack just below the sticking position of the strain gauge, the measured CFRP strain value here will be significantly larger than the other locations nearby. On the contrary, if the strain gauge is located above the concrete aggregate, the strain measured here will be much smaller than the that at the adjacent position.

In order to reduce the local bond-slip relationship measured in different specimens, the slip value in the local micro-segment will be obtained by the superposition method. The local bond shear stress can be obtained by calculating the strain value of adjacent strain gauges. It can be calculated according to the following formula:

$$
\tau_{i}=t_{f} \cdot \frac{d \sigma_{f i}}{d x}=t_{f} \cdot E_{f} \cdot \frac{d \varepsilon_{f i}}{d x}
$$

Where $\tau_{i}$ and $E_{f}$ are the shear stress and the elastic modulus of CFRP plate, respectively; $t_{f}$ is the thickness of CFRP plate; $d \sigma_{f i}$ and $d \varepsilon_{f i}$ are the differential of normal stress and the differential of strain, respectively; $d x$ is the length of local micro-segment.

The local micro-segment slip at the FRP-concrete interface can obtained by the superposition method, and it can be calculated by the following equations:

$s=\frac{\Delta w_{c r}}{2}-\frac{\varepsilon_{0} \cdot g_{s}}{2}$

$\varepsilon_{0}=\frac{p}{2 b_{f} \cdot t_{f} \cdot E_{f}}$

Where $s$ is the slip value, $\Delta w_{c r}$ is the relative slip between the concrete blocks, $\varepsilon_{0}$ is the initial strain, $g_{s}$ is the spacing between the strain gauges. And $b_{f}$ is the width of CFRP plate, $p$ is load applied to the interface.

The test results are submitted into the Equations (1) to (3), and the shear stress of the CFRP-concrete interface can be obtained. For convinence of observation, the calculation results are normalized, and the normalized shear stress is shown in Figure 10.
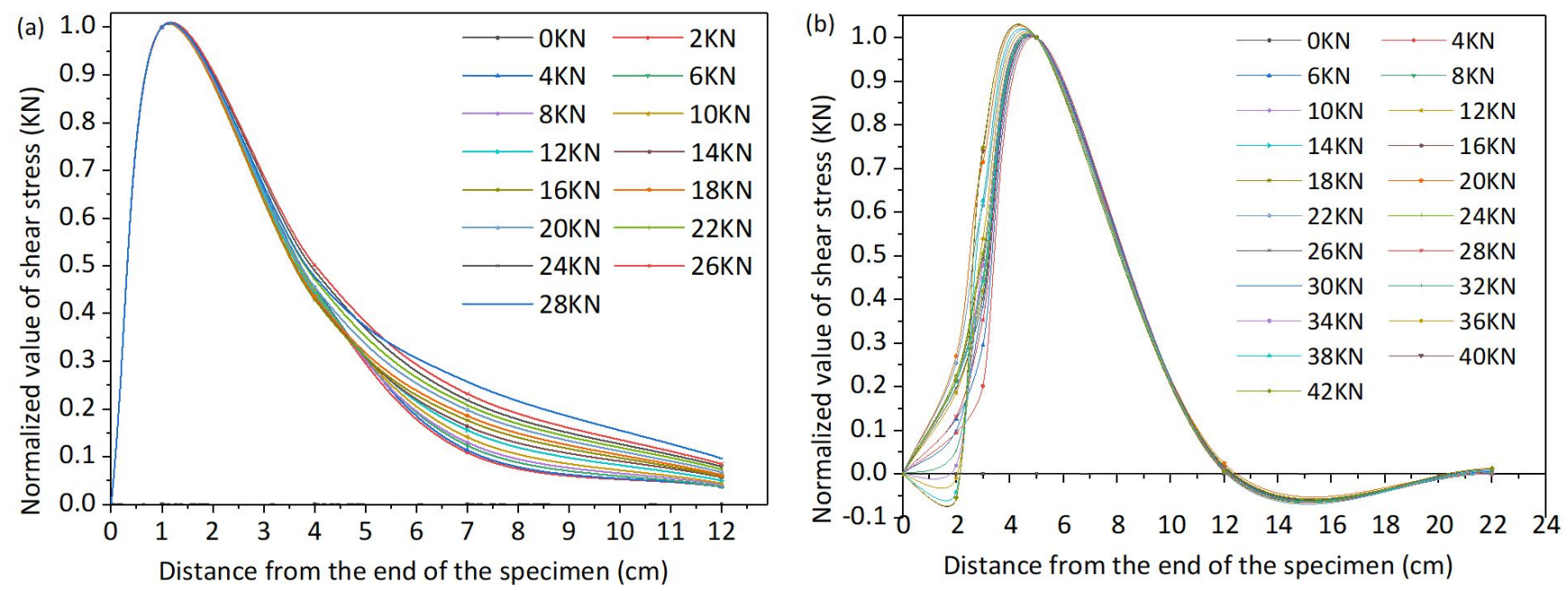

Figure 10 Change trend of the interfacial shear stress between CFRP plate and concrete: (a) specimens in G-1; and (b) specimens in G-2. 
It can be seen from the Figure 10 that since the load acting on the CFRP plate near the loading end is transmitted to the concrete through the interface layer. The effect of the interface adhesive layer participating in the transmission force is smaller as the distance from the loading end is further.

As the load increases, the shear stress at the loading end increases sharply. The distribution area gradually expands to a range of about $100 \mathrm{~mm}$. When the load increases to a certain value, the shear stress distribution region no longer grows, and the shear stress at the loading end reaches a maximum value. As the load is further increased, the shear stress value at the loading end begins to decrease, and the position of the maximum shear stress begins to move toward the free end. The shear stress distribution curve begins to gradually appear in the form of a normal distribution curve. As the load continues to be applied, the shear stress distribution curve continues to move toward the free end, and the shear stress near the loading end decreases to zero, indicating that the interface begins to debonding until the interface of the specimen is completely debonded.

\section{INTERFACIAL BOND-SLIP ANALYSIS MODEL}

\subsection{Existing interfacial bond-slip models}

The establishment of CFRP-concrete interface bond-slip constitutive relationship is the basis of interface force analysis. The existing models can be divided into three main categories: empirical models that are directly derived from experimental data, fracture mechanics models, and design formulas that use simplified assumptions. From the curve form, it can be mainly divided into right triangle type, double line type, hyperbolic type and so on. The curve shape of different bond-slip models is shown in Figure 11.

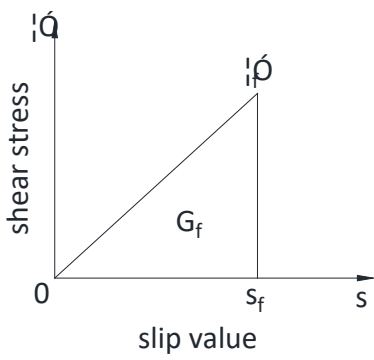

(a)

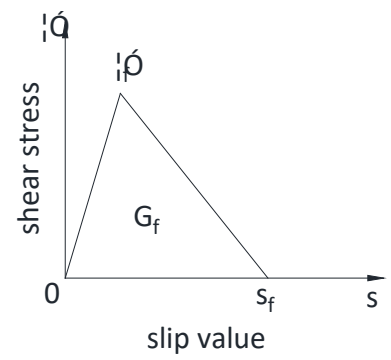

(b)

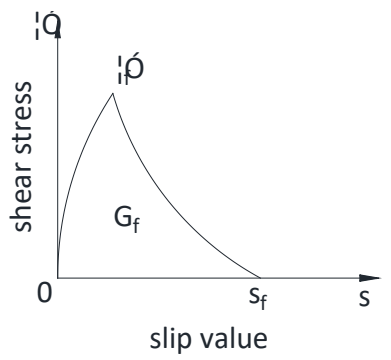

(c)

Figure 11 Curve shape of interface bond slip constitutive model: (a) right triangle type; (b) double line type; and (c) hyperbolic type. (Where $\tau_{f}$ is the maximum interface shear stress, $\mathrm{s}_{\mathrm{f}}$ is the maximum slip value, $\mathrm{G}_{\mathrm{f}}$ is the interface shear fracture energy)

The typical right triangle type model was proposed by Neubauer et al, and the formula of the model is as follows.

$$
\left\{\begin{array}{cc}
\tau=\tau_{\max }\left(\frac{s}{s_{0}}\right) & s \leq s_{0} \\
\tau=0 & s>s_{0}
\end{array}\right.
$$

Where $\tau$ and $s$ are the local bond stress and slip value. $\tau_{\max }$ is the maximum bond stress, and $s_{0}$ is the slip value corresponding to $\tau_{\max }$.

The existing model in double line type was first proposed Monti et al. (2003), and the function is as follows.

$$
\left\{\begin{array}{cc}
\tau=\tau_{\max }\left(\frac{s}{s_{0}}\right) & s \leq s_{0} \\
\tau=\tau_{\max }\left(\frac{s_{f}-s}{s_{f}-s_{0}}\right) & s_{0}<s \leq s_{f} \\
\tau=0 & s>s_{f}
\end{array}\right.
$$


Where $s_{f}$ is slip value corresponding to the circumstance that bond stress is equal to zero.

Nakaba et al. (2001) proposed an interfacial bond slip constitutive model in hyperbolic type, and the function is shown as Equation (6). Savoia et al. (2003) modified the model base on the study of Nakaba et al., and the model suggested is shown as Equation (7).

$$
\begin{aligned}
& \tau=\tau_{\max }\left(\frac{s}{s_{0}} \frac{3}{2+\left(s / s_{0}\right)^{3}}\right) \\
& \tau=\tau_{\max }\left(\frac{s}{s_{0}} \frac{2.86}{1.86+\left(s / s_{0}\right)^{2.86}}\right)
\end{aligned}
$$

Among the proposed models above, the model in double line type is relevantly simple in describing the interface behavior between CFRP and concrete, and is widely accepted in practice. While the hyperbolic model is closer to the actual situation than the double line model in terms of curve shape.

\subsection{Proposed model for interface after high temperature influence of asphalt paving construction}

\subsubsection{Bond-slip relationship curve}

By comparing the above existing constitutive models, it can be seen that the bond-slip model of CFRP-concrete interface is better by adopting the hyperbolic type. The details of the model curve are shown in Figure 12 . The abscissa in the figure represents the slip value of the interface; the ordinate represents the bond shear stress of the interface. The horizontal axis in the figure represents the slip value of the interface; the longitudinal axis represents the interfacial bond shear stress of the interface. In this figure, $\tau_{t}, \tau_{c r}$ and $\tau_{\max }$ are the terminal value, critical value and peak value of interfacial shear stress, respectively. $s_{0}$ is the slip value corresponding to the peak shear stress, and $s_{u}$ is the ultimate slip value

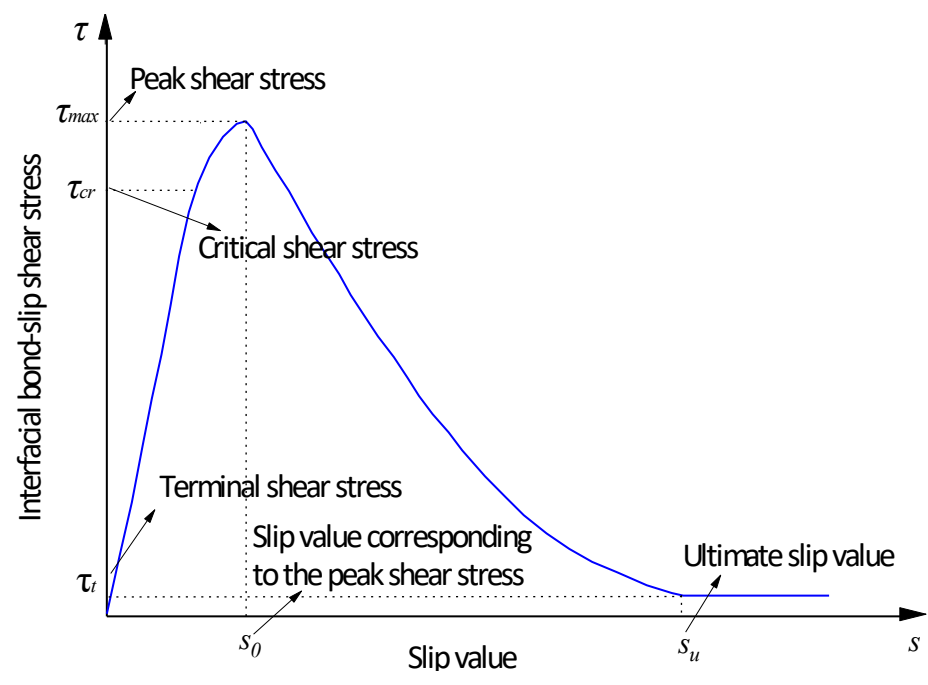

Figure 12 Bond-slip model of CFRP plate -concrete interface.

It can be seen from the Figure 12 that the interfacial bond-slip curve generally has obvious nonlinearity and interface softening characteristics, and the curve mainly consists of a rising section and a falling section. The curve has the following characteristics:

(1) For the phase from 0 to $\tau_{c r}$, the curve is approximated as a straight-line segment. At this stage, the interfacial adhesion is mainly provided by the chemical bonding force between the concrete and the adhesive. The interface bonding rigidity is large at this time. 
(2) In the stage of $\tau_{c r}$ to $\tau_{\max }$, when the interfacial shear stress exceeds the cementation stress, local slippage begins to occur. As the slip increases, the rate of increase of the bond stress gradually decreases.

(3) In the $\tau_{\max }$ to $\tau_{t}$ stage, the interface is damaged and cannot withstand the shear stress released by the bonded section. As the slip increases, the cohesive force decreases approximately linearly.

(4) When the shear stress drops to $\tau_{t}$, the interface will be debonded at this time. The bond stress is all provided by the friction force and the mechanical bite force between the CFRP plate and concrete.

It can be seen from the above analysis that the key parameters of the bond-slip curve include the critical shear stress $\tau_{c r}$, the stress peak $\tau_{\max }$, the limit slip amount $s_{u}$, and the slip amount $s_{0}$ corresponding to the stress peak. The key parameter values of the bond-slip curve of each specimen in this test can be calculated as shown in Table 3 .

Table 3 Calculated key parameter values for the bond-slip curve.

\begin{tabular}{|c|c|c|c|c|c|c|c|c|c|c|c|}
\hline \multirow{5}{*}{ G-1 } & Specimen number & $\begin{array}{c}\tau_{\mathrm{cr}} \\
(\mathrm{MPa})\end{array}$ & $\begin{array}{c}\tau_{\max } \\
(\mathrm{MPa})\end{array}$ & $s_{0}(m m)$ & $s_{\mathrm{u}}(m m)$ & \multirow{5}{*}{ G-2 } & Specimen number & $\begin{array}{c}\tau_{\mathrm{cr}} \\
(\mathrm{MPa})\end{array}$ & $\begin{array}{c}\tau_{\max } \\
(\mathrm{MPa})\end{array}$ & $s_{0}(m m)$ & $s_{\mathrm{u}}(m m)$ \\
\hline & DS-1 & 5.03 & 5.98 & 0.050 & 0.40 & & DS-4 & 4.96 & 6.09 & 0.06 & 0.40 \\
\hline & DS-2 & 5.3 & 6.00 & 0.055 & 0.39 & & DS-5 & 4.8 & 5.95 & 0.005 & 0.39 \\
\hline & DS-3 & 4.52 & 5.96 & 0.051 & 0.44 & & DS-6 & 5.60 & 5.99 & 0.069 & 0.38 \\
\hline & Average value & 4.95 & 5.98 & 0.052 & 0.41 & & Average value & 5.12 & 6.01 & 0.045 & 0.39 \\
\hline
\end{tabular}

An interfacial bond-slip curve can be obtained by fitting the calculated key parameter values, and the interfacial bond-slip curve model is as shown in Figure 13. It can be seen from the figure that the difference between the interfacial bond-slip curve after high temperature action and that under ordinary temperature is not obvious from the shape of the curve.

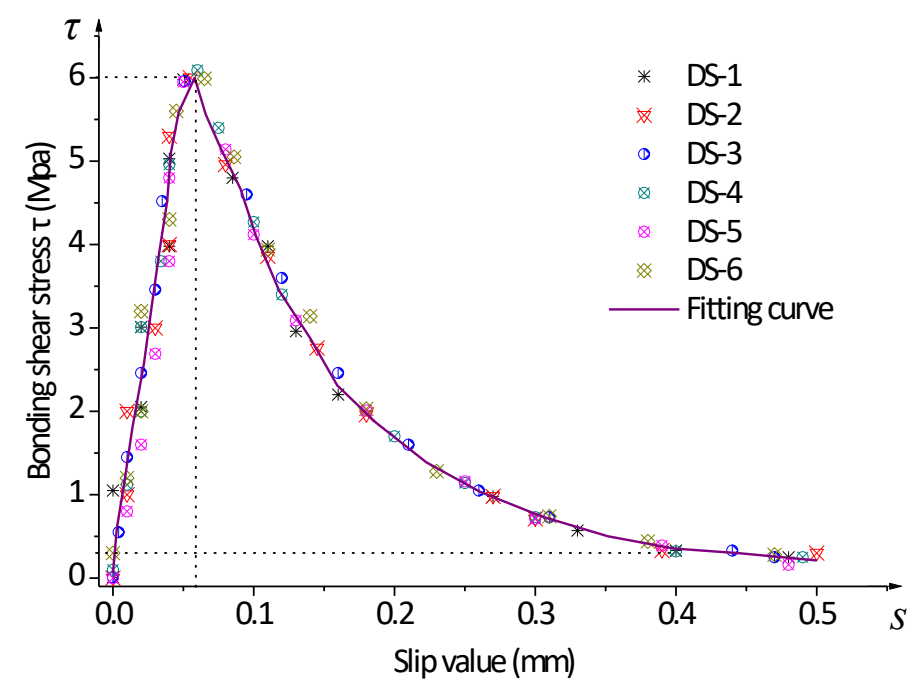

Figure 13 Interfacial bond-slip curve model of CFRP plate-concrete after high temperature action.

\subsubsection{Interfacial bond-slip constitutive model}

Based on the previous analysis, the CFRP-concrete interface bond-slip curve obtained is basically composed of two curves: the ascending segment and the descending segment. The hyperbolic model can be directly used in the CFRP plate-concrete interfacial bond-slip model. According to the curve characteristics and combined with the hyperbolic model proposed by Guo et al. (2007), the model is further modified based on the experimental data of this paper to satisfy the governing equation shown as the following formula: 


$$
\left\{\begin{array}{lc}
d \tau / d s=k_{0} & (s=0) \\
\tau / \tau_{\max }=1, d \tau / d s=0 & \left(s=s_{0}\right) \\
d \tau / d x=u, d \tau / d s \rightarrow 0 & \left(s=s_{u}\right)
\end{array}\right.
$$

Where $k_{0}$ is the stiffness of initial bonding interface, $u$ is a constant, and $\tau$ is the interfacial shear stress. $d s$ and $d \tau$ are the differential of the slip value and the interfacial shear stress.

Referring to the existing bond strength model of CFRP reinforced concrete structure, the interface bond-slip model of CFRP plate-concrete under high temperature action is recommended in hyperbolic type, and the expression is as follows.

$\begin{cases}\frac{\tau}{\tau_{\max }}=\left(\frac{s}{s_{0}}\right)^{a} & \left(s \leq s_{0}\right) \\ \frac{\tau}{\tau_{\max }}=e^{-b\left(\frac{s}{s_{0}}-1\right)} & \left(s>s_{0}\right)\end{cases}$

Where $a$ and $b$ are the regression coefficient, respectively.

The values of the regression coefficients $a$ and $b$ can be obtained by numerical analysis fitting based on the experimental data. The results of fitting the experimental data are: $a=0.739, b=0.428$, and the model is shown as Figure 14. It can be seen from the figure that the test results and the proposed model curve have good agreement due to the existence of the rising and falling parts of the hyperbolic model.

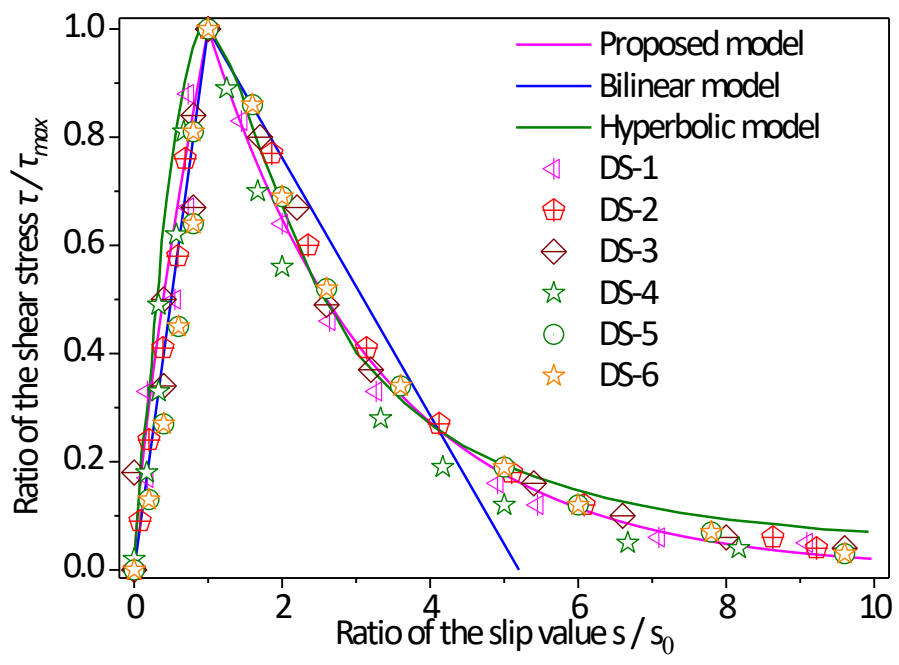

Figure 14 Comparison of CFRP plate-concrete bond-slip model. (Where $\tau$ is the interfacial stress peak, $\tau_{\max }$ is the interfacial stress peak value, $s$ is the slip value, $s_{0}$ the slip value corresponding to $\tau_{\max }$ )

In practical engineering applications, two main curve characteristic parameters that need to be determined for the interfacial bond-slip model are the interfacial stress peak value $\tau_{\max }$ and the corresponding slip value so. Since the failure mode of the CFRP plate-concrete interface is often manifested as the debonding of the surface concrete, the interfacial shear stress peak $\tau_{\max }$ is closely related to the concrete strength performance.

When the adhesive layer penetrates into the concrete layer, it can produce chemical bonding force. It can enhance the bonding ability of the interface together with the mechanical force and the friction force between the adhesive layer and the concrete layer. In the case where the CFRP pasting width is smaller than the width of the concrete member, when the stress is transmitted to the concrete through the CFRP plate, uneven distribution of stress within the concrete member may be caused. Therefore, the width ratio coefficient proposed by Chen and Teng (2001) is introduced and the formula is as follows: 


$$
\beta_{w}=\sqrt{\frac{2-b_{f} / b_{c}}{1+b_{f} / b_{c}}}
$$

Where $\alpha_{b}$ and $B_{w}$ are the bonding enhancement coefficient and width ratio coefficient, respectively. $f_{c t m}$ is the tensile strength of concrete surface, $b_{f}$ is the bonding width of CFRP plate and $b_{c}$ is the width of concrete specimen.

It is difficult to obtain the concrete surface tensile strength $f_{c t m}$ in actual engineering, so the conversion formula of the concrete cube compressive strength $f_{c u}$ is generally used instead. Therefore, Equation 10 can be converted into the following formula:

$$
\tau_{\max }=0.474 \alpha_{b} \cdot \beta_{w} \cdot \sqrt{f_{c u}}
$$

It can be learnt from the double shear test results, the shear stress peak value $\tau_{\max }$ is at the range of 5.95-6.09 $\mathrm{MPa}$. According to the test results, the average value of each interface stress peak is $6 \mathrm{MPa}$ for fitting calculation. The fitting result shows that the bond enhancement coefficient $\alpha_{b}$ is taken 1.668 .

For the slip value $s_{0}$, it is mainly related to the mechanical properties of the FRP plate, the mechanical properties of the adhesive layer and concrete, and the mechanical properties of the infiltration layer of the adhesive layer and the concrete. Although a calculation formula related to the shear stiffness of the adhesive layer and the shear modulus of the concrete based on the fine finite element method was proposed by Lu et al. (2005), no effective verification is given. The slip value $s_{0}$ is generally obtained through tests, and the recommended slip value is $0.05 \mathrm{~mm}$.

In conclusion, for the interfacial bond-slip constitutive relation for the CFRP plate-concrete under the high temperature action of asphalt paving construction, the recommended model is as follows:

$$
\begin{aligned}
& \begin{cases}\frac{\tau}{\tau_{\max }}=\left(\frac{s}{0.05}\right)^{0.741} & (s \leq 0.05) \\
\frac{\tau}{\tau_{\max }}=e^{-0.433\left(\frac{s}{0.05}-1\right)} & (s>0.05)\end{cases} \\
& \tau_{\max }=0.8 \beta_{w} \cdot \sqrt{f_{c u}}
\end{aligned}
$$

The main curve characteristic parameter values obtained in the previous calculation are substituted into the CFRP plate-concrete interface bond-slip constitutive model proposed in this paper, and compared with the existing bond-slip constitutive model proposed by Savoia et al. (2003), Nakaba et al. (2001), Neubauer and Rostasy (1999), and Monti et al. (2003). The interfacial bond-slip constitutive model of CRFP plate-concrete after the high temperature action of asphalt paving construction is shown in Figure 15. 


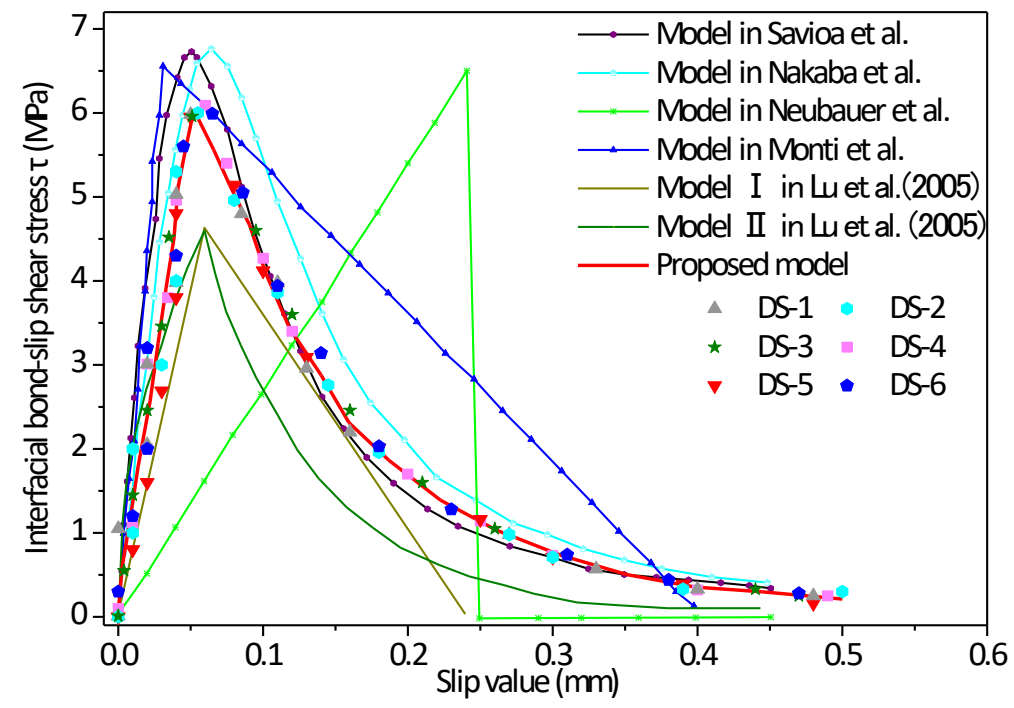

Figure 15 Comparison of FRP plate-concrete interfacial constitutive model.

Although the asphalt temperature is very high during the paving construction process, due to the protection of the heat insulation layer, the temperature transferred to the CFRP plate is not so high. The temperature of the CFRP plate can remain relatively stable during the normal use phase. It can be seen from the Figure 15 that the overall trend of the interfacial bond-slip constitutive model of CFRP-concrete after the high temperature action is similar to other interfacial bond-slip constitutive models.

\section{CONCLUSIONS}

This paper investigated the bonding property of CFRP reinforced concrete structure after high temperature action of SMA paving construction. Several double shear specimens were tested to study the interfacial property of CFRP plate-concrete structure and typical failure modes of specimens. An interfacial bond-slip constitutive model for CFRP plate-concrete structure after high temperature action of paving SMA was proposed. It can be used to predict the bond-slip behavior of the CFRP plate and concrete after high temperature action. Several conclusions can be drawn as follows:

(1) The failure modes of specimen can be divided into the bond failure of CFRP plate and the splitting tensile failure of the protection layer.

(2) The interfacial bond-slip constitutive model exhibits significant nonlinearity and interfacial softening properties under this special environment

(3) The interface of CFRP plate and concrete can still maintain good anti-sliding performance after the SMA paving high temperature action.

(4) The model proposed in this paper can effectively predict the bond-slip behavior between CFRP plate and concrete after high temperature action.

\section{Acknowledgements}

This work was financially supported by the National Natural Science Foundation of China (Grant No. 51508368), the Postgraduate Research \& Practice Innovation Program of Jiangsu Province (Grant No. SJCX18_0879), and the Key Project of Innovation and Entrepreneurship of College students in Jiangsu Province (Grant No. 201810332019Z).

Author's Contributions: Conceptualization, $X$ Yuan, $Y$ Zhang and C Zhu; Methodology, $X$ Yuan and C Zhu; Investigation, $X$ Yuan, Y Zhang, C, Zhu, W Zheng, and B Tang; Writing - original draft, X Yuan, C Zhu and W Zheng; Writing - review \& 
editing, $X$ Yuan, $Y$ Zhang and B Tang; Funding acquisition, X Yuan and C Zhu; Resources, X Yuan and C Zhu; Supervision, $X$ Yuan, $Y$ Zhang and B Tang.

Editor: Marcílio Alves.

\section{References}

Alhassan, M. A., Rousan, R. Z. A., and Shuqari, E. A. A., (2019). Bond-slip behavior between fiber reinforced concrete and CFRP composites. Ain Shams Engineering Journal 10: 359-367.

Al-Rousan, R. Z., AL-Tahat, M, F., (2019). Consequence of surface preparation techniques on the bond behavior between concrete and CFRP composites. Construction and Building Materials 212:362-374.

Bocciarelli, M., Colombi, P., D’Antino, T., and Fava, G., (2018). Intermediate crack induced debonding in steel beams reinforced with CFRP plates under fatigue loading. Engineering Structures 171: 883-893.

Çelebi, M., Özgür A., and Cengizhan, D., (2016). Bond slip behavior of anchored CFRP strips on concrete surfaces. Construction and Building Materials 123(1): 553-564.

Chataigner, S., Benzarti, K., Foret, G., Caron, J.F., Gemignani, G., Brugiolo, M., Calderon, I., Piñero, I., Birtel, V., and Lehmann, F., (2018) Design and testing of an adhesively bonded CFRP strengthening system for steel structures. Engineering Structures 177: 556-565.

Chen, J. F. and Teng, J. G., (2001). Anchorage Strength Models for FRP and Steel Plates Bonded to Concrete. Journal of Structural Engineering 127(7): 784-791.

Chung, L., Hur, M. W., and Park, T. (2018). Performance Evaluation of CFRP Reinforced Concrete Members Utilizing Fuzzy Technique. International Journal of Concrete Structures and Materials 12:78.

Dong, K., and Hu, K. X., (2016). Development of bond strength model for CFRP-to-concrete joints at high temperatures. Composites Part B 95: 264-271.

Firmo, J. P., Correia, J. R., Pitta, D., Tiago, C., and Arruda M. R. T., (2015). Experimental characterization of the bond between externally bonded reinforcement (EBR) CFRP strips and concrete at elevated temperatures. Cement and Concrete Composites 60: 44-54.

Gallego, J. M., Michels, J., and Czaderski, C., (2017). Influence of the Asphalt Pavement on the Short-Term Static Strength and Long-Term Behaviour of Rc Slabs Strengthened with Externally Bonded Cfrp Strips. Engineering Structures 150: 481-496.

Guo, Z., Sun, W. and Cao, S., (2007). Experimental study on bond-slip behavior between FRP and concrete. China Civil Engineering Journal 40(3): 1-5.

Haddad, R. H., (2019). An Anchorage System for Enhanced Bond Behavior between Carbon Fiber Reinforced Polymer Sheets and Cracked Concrete. Latin American Journal of Solids and Structures 16(8): e222

Hager, I., (2013). Behaviour of cement concrete at high temperature. Bulletin of the polish academy of sciences-technical sciences 61(1): 145-154.

Hawileh, R. A. Rasheed, H. A. Abdalla, J. A., and Al-Tamimi, A. K., (2014). Behavior of reinforced concrete beams strengthened with externally bonded hybrid fiber reinforced polymer systems. Materials \& Design 53: 972-982.

Jeon, Y., Lopez, M. M., and Bakis, C. E., (2016). Effects of temperature and sustained loading on the mechanical response of CFRP bonded to concrete. Construction and Building Materials 124: 442-452.

Lepretre, E., Chataigner, S., Dieng, L., and Gaillet, L., (2018). Fatigue strengthening of cracked steel plates with CFRP laminates in the case of old steel material. Construction and Building Materials 174: 421-432.

Li, K., Cao, S. Y., Yang, Y., and Zhu, J. T., (2018). Bond-slip relationship for CFRP sheets externally bonded to concrete under cyclic loading. Materials 11(336): 1-14. 
Liang, H. J., Li, S., Lu, Y. Y. and Yang, T., (2019). The combined effects of wet-dry cycles and sustained load on the bond behavior of FRP-concrete interface. Polymer Composites: 1006-1017.

Lu, X. Z., Teng, J. G., Ye, L. P. and Jiang, J. J., (2005). Bond-slip models for FRP sheets/plates bonded to concrete. Engineering Structures 27(6): 920-937.

Martin, H., Viviane, A., Martin, C., Dominik, K. and Josef, H., (2017). Strengthening of Existing Bridge Structures for Shear and Bending with Carbon Textile-Reinforced Mortar. Materials 10(9): 1099.

Mashrei, M.A., Makki, J.S., and Sultan, A.A., (2019). Flexural strengthening of reinforced concrete beams using carbon fiber reinforced polymer (CFRP) sheets with grooves. Latin American Journal of Solids and Structures 16(4): e176.

Monti, M., Renzelli, M. and Luciani, P., (2003). FRP adhesion in uncracked and cracked concrete zones. Proc. 6th International Symposium on FRP Reinforcement for Concrete Structures World Scientific Publications, Singapore.

Nakaba, K., Kanakubo, T., Furuta, T. and Yoshizawa, H., (2001). Bond behavior between fiber-reinforced polymer laminates and concrete. ACl Structural Journal 98(3): 359-367.

Neubauer, U. and Rostasy, F. S., (1999). Bond failure of concrete fiber reinforced polymer plates at inclined cracks-experiments and fracture mechanics model. International Symposium on Fiber Reinforced Polymer Reinforcement for Reinforced Concrete Structures: 369-382.

Pan, Y. F., Xian, G. J. and Li, H., (2018). Effects of freeze-thaw cycles on the behavior of the bond between CFRP plates and concrete substrates. Journal of Composites for Construction 22(3)-04048011:1-14.

Pan, Y. F. and Xian, G. J., (2019). Influence of long-term outdoor exposure in a frigid zone on the CFRP-to-concrete bond behaviour. Construction and Building Materials 215: 462-474.

Rajai,A., Mohammad, A., Ayman, A., (2016). Simulating the response of CFRP strengthened shear-keys in composite concrete bridges. Materials \& Design 90: 733-744.

Rukavina, T., Ibrahimbegovic, A., and Kozar, I., (2019). Multi-scale representation of plastic deformation in fiber-reinforced materials: Application to reinforced concrete. Latin American Journal of Solids and Structures 16(7): 1-11.

Savoia, M., Ferracuti, B. and Mazzotti, C. (2003). Non-linear bond-slip law for FRP-concrete interface. Procedings of 6th International Symposium on FRP Reinforcement for Concrete Structures: 163-172, Singapore: World Scientific Publications.

Shan, B., Pan, Y., Huo, X., and Xian, G., (2018). Detection of slip for CFRP - concrete interface using stereovision method corrected by epipolar constraint. Structurl Control Health Monitoring 25: e2212.

Siddika, A., Mamun, Md. A.A., Alyousef, R., and Amran, Y.H.M. (2019). Strengthening of reinforced concrete beams by using fiber-reinforced polymer composites: A review. Journal of Building Engineering 25: 100798.

Wang, X. L., Zhao, G. Q., Li, k. and Li, M. H. F. (2018). Effect of damage parameter variation on bond characteristics of CFRPsheets bonded to concrete beams. Construction and Building Materials 185: 184-192.

Wanga, X.M., and Petrů, M., (2019). Mode I fracture evaluation of CFRP-to-concrete interfaces subject to aggressive environments agents: Freeze-thaw cycles, acid and alkaline solution. Composites Part B 168: 581-588.

Yazdani, N., Beneberu, E., and Riad, M. (2019). Nondestructive Evaluation of FRP-Concrete Interface Bond due to Surface Defects. Advances in Civil Engineering 2563079.

Yin, Y. S., and Fan, Y. F., (2018). Influence of roughness on shear bonding performance of CFRP-concrete interface. Materials 11(1875): 1-15.

Yuan, X., Zhu, C., Hu J., and Zhang, Y. (2019). crack and mechanical behavior of CFRP plate-reinforced bridge roofs under high temperature with different anchoring measures. Latin American Journal of Solids and Structures 16(6), e206.

Zeng, J. J., Gao, W. Y., and Liu, F., (2018). Interfacial behavior and debonding failures of full-scale CFRP-strengthened H-section steel beams. Composite Structures 201: 540-552.

Zhu, J. T., Wang, X. L., Kang, X. D. and Li, K., (2016). Analysis of interfacial bonding characteristics of CFRP-concrete under fatigue loading. Materials \& Design 96: 823-833. 
Zhuang, N., Dong, H.H., Chen, D., and Ma, Y.M. (2018). Experimental study of aged and seriously damaged RC beams strengthened using CFRP composites. Advances in Materials Science and Engineering 6260724.

Zhang, S.S., Yu, T., and Chen, G.M., (2017). Reinforced concrete beams strengthened in flexure with near-surface mounted (NSM) CFRP strips: Current status and research needs. Composites Part B: Engineering 131: 30-42. 